GRI-rapport 2008:2

The moral responsibility of project selectors

Hervé Corvellec \& Nikos Macheridis

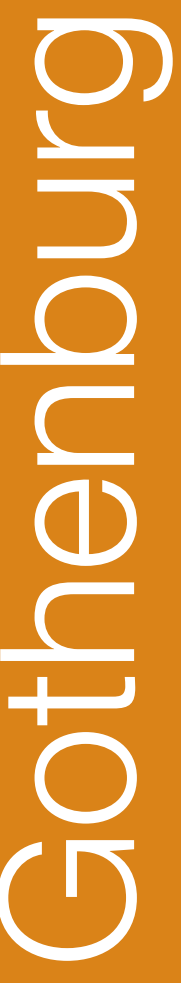


(C) Gothenburg Research Institute

All rights reserved. No part of this report may be reproduced without the written permission from the publisher.

Gothenburg Research Institute

School of Business, Economics and Law

at Göteborg University

P.O. Box 600

SE-405 30 Göteborg

Tel: +46 (0)31 - 7865413

Fax: +46 (0)31 - 7865619

E-post: gri@gri.gu.se

ISSN 1400-4801

Layout: Lise-Lotte Walter 



\title{
The moral responsibility of project selectors
}

\begin{abstract}
The starting point of this paper asserts that managers who elicit and select projects have a moral responsibility. Correspondingly, its purpose is to provide a means for project selectors to appreciate this responsibility so that it can be put into practice. A model of the moral responsibility involved in project selection is presented. This model combines a) an explication of responsibility into attributability - what choices the project manager can ultimately be praised or blamed for, and accountability - the necessity of being prepared to answer for one's choices; with b) an explication of the project selection process into an initialisation phase, an appraisal phase, and a decision phase. Various moral philosophers are called upon to make explicit the moral issues that are at stake for each of these two dimensions of responsibility at each stage of the project selection process. Concluding remarks point to the need for project selectors to contextualise their use of the model.
\end{abstract}

Keywords

Project selection, Ethics, Responsibility. 



\section{Introduction}

When more and more organisational activities become structured as projects, more and more managers need to involve themselves with project selectionthe decision about which projects should be carried out and which should not. Project selection is typically about choosing one or several projects among several proposals, such as in the cases of a competition between in-house projects, competitive tendering, or grant allocation; but it can even consist of deciding whether a single proposal should be carried out or not, such as in the case of an organisational development project. It is a managerial situation that concerns all kinds of projects, and can take place in intra-organisational contexts (i.e. when projects are to be undertaken within an organisation) as well as in interorganisational contexts (i.e. when projects are to be undertaken between two or more organisations).

Selecting projects entails numerous risks and difficulties, though. Selectors usually intervene early in the project's life cycle, for example during its conceptual phase [1]. At this moment, actual work with project management has not yet begun, and the project is only a hard to assess, "might-become" proposal. The difference between ex-post evaluation of projects or the purchase of turn-key services is that there is not necessarily much to assess except for future potential. Moreover, this potential has to be assessed on several dimensions. Project selectors need to pay careful attention to operational matters such as the resources in use, the competence of the project team, and legal aspects of the project. They also need to weigh in strategic considerations such as symbolic and financial implications, or environmental impact. Project proposals are hard to test as bets on their future potential.

An additional, although much less acknowledged, difficulty of project selection is that a selector's agential power to say "yes" or "no" will have an impact on people, the economy, or the environment. Thus the decision involves an encompassing responsibility. One immediately thinks of legal and economic responsibilities. Our claim, and our focus in this paper, is that this responsibility also has an ethical side and that project selectors should be aware of it.

The moral responsibility of managers who select projects mirrors the responsibility of project managers to ensure decent ethical standards in their projects [e.g.: 2, 3]. Selectors are responsible to design a selection process that is fairly and competently conducted. They even have to ensure that the projects they promote will have an acceptable impact on the parent company, project participants, local communities, and the environment. Project selection is thus more akin to the purchase of a complex service than to an abstract mathematical processing of a given set of possible choices. It is a professional commitment.

Our purpose in this paper is to offer a model to describe the moral responsibility of project selectors. In order to do so, we first explicate responsibility as being composed of attributability or what the project manager can be praised or blamed 
for, and accountability or before whom the project manager can be summoned to answer for the consequences of the choices having been made. Further, we explicate the project selection process as composed of an initialisation phase, an appraisal phase, and a decision phase. Combining these two explications, the model makes it possible to assess the moral responsibility of project selectors both with regard to what they can be held responsible for and who they are responsible before. It also covers the selection process from the choice of criteria of eligibility or the invitation of projects to compete, to the communication of the decision about which project(s) have been retained, through the evaluation of the candidates in competition.

\section{Project selection}

The business case for projects as an organisational mode needs hardly to be made any longer. Contemporary organisations have broadly embraced temporary modes of organising [4] for many reasons, among which are their embeddedness [5] and responsiveness [6]. A consequence is that more and more middle and top level managers face the difficult challenge to collect and evaluate project proposals, and aptly select which will be carried out and which will not.

Project selection has been defined as "the process of evaluating individual projects or groups of projects and then choosing to implement a set of them so that the objectives of the parent organization are achieved" [7]. This is a definition that aptly frames project selection not only in terms of what it involves, namely a series of managerial situations that goes from evaluation to selection (more about the phases of this process in section 4 below), but also in terms of what this selection is intended to accomplish, namely to serve the interests of the parent organization. Project selection is a process of strategic significance $[8,9$, $10]$ where each phases matters.

In the vocabulary of agency theory [11], a project selector appears to be a principal who steers a project team which acts as an agent. The selector also appears to be an agent of the parent organisation who acts as a principal. Selectors are thus doubly exposed, both as principals and as agents, to the classic agency problems of diverging goals, information asymmetry, outcome uncertainty, moral hazard, imperfect contracts, manipulatable rewards systems, or conditional trust. (See [12], [13], and [14] for formalised applications of agency theory to project selection).

Project selection takes place early in the project's lifecycle. Some would even say it occurs before the actual lifecycle of the project since one could consider that a project is not really a project but only a proposal until there is any concrete plan to realise it. Selection can deal with ideas, outlines, sketches, or plans depending on the degree of sophistication of the proposals. It can also deal with different kinds of projects [15]. For example, the selection of a compliance project will 
focus on the project's ability to meet regulatory conditions whereas the selection of an emergency project, such as rebuilding a factory destroyed by fire, will focus on its ability to meet the company's more immediate needs. Likewise, operational projects are selected to support current operations whereas strategic ones are chosen to serve the organization's long-run mission. It is legitimate to speak of project selection even when only one proposal is involved since there is always a choice to make between the proposal and the zero solution. Consequently, even projects that are not subjected to any formal review process, for example because they are deemed to be strategically important by top representatives of the parent organization, are subjected to a project selection process.

A series of variables impacts on the nature of the selection process from project size to expected duration through resources in use to risks (both the ones inherent to the project and the ones taken on by the parent organisation). Even the fact that a project involves the public sector can be of relevance $[16,17]$.

There are varied ways to select projects. Some distinguish between financial and non-financial models [15]. Others prefer to speak of numeric and nonnumeric methods [18]. Among nonnumeric methods, one can mention the operating-competitive necessity model upon which is selected any project that is necessary for continued operations or for a maintenance of competitive position; one can also mention the comparative position method upon which members in a selection committee rank-order potential projects and retain the best ones, either in a single set if there are few projects, or in different subsets such as "good," "fair," and "poor" if the number of projects is too high.. Among numeric selection methods, one can mention financial methods upon which one assesses the expected economic value of projects, for example, as a payback period or a net present value, two methods that require accurate costs [19] and income forecasts. More sophisticated approaches combine Delphi, analytic network process and goal programming methods [20]; others bring together expected economic outcomes with risk exposure to offer a portfolio approach to project selection [21]; yet others rely on fuzzy set mathematics to process uncertain information $[22,23]$. Other numeric selection methods are the scoring methods upon which projects are given a weighted score according to a pre-defined set of criteria. None of these methods is supreme. Some are tightly controlled by internal or external experts whereas others give considerable leeway to stakeholders. What matters for a selection method is that it is sophisticated and flexible enough, through all the phases of project selection, to deal with various situations, kinds of projects, and time periods, while it is at the same time adaptable enough to the mangers' decision situation and simple enough that selectors can use it with ease and at an acceptable cost [18].

Finally, selectors are invited to adopt a broad view of a project when doing their selection. They are invited to take into consideration information pertaining to varied operational aspects of the project, such as production, marketing, finance, or personal administration as well as strategic ones, such as long term impact 
on the parent organisation's performance. They are also increasingly invited to take uncertainty and risk into consideration [24]. It is therefore all the more remarkable that the moral dimensions of their choices have so far received so little attention.

\section{The moral responsibility of project selectors}

Selectors have much influence in the realisation of projects. Acting as gatekeepers, they partake in the discretionary power to make it possible for this project, but not for that project, to become reality. As key agents of the selection process, they have the potential to affect the use of resources, to orient how people will spend their time or energy, and to settle whether the nature, scope, or time-scale of a project's outcomes should be accepted or not. To put it briefly, project selectors have some agentic power to shape the future of profits, people, and the planet. A major consequence is that this implies a corresponding responsibility (after John Elkington's [25] triple bottom line argument).

This responsibility is not simply legal and economic; it is also ethical [26]. Because project selectors can say "yes" or "no" (and of course many things inbetween), they are, as professionals, subordinated to what Max Weber [27] calls an ethics of responsibility. Their decisions cannot only rely on their pure ethical convictions as individuals. They are also facing a moral imperative to consider the foreseeable consequences of their agency, for others and the environment.

Contemporary moral philosophy adds to this that being responsible is not only a matter of being blameworthy for having caused some harm or praiseworthy for having caused some good; it is also a matter of owing a response [28]. Responsibility is both attributability and accountability. To be responsible is to be ready to see one's actions assessed in terms of a causal attribution of blame or praise. However, and although legal and therefore economic responsibility often stays at attributability, to be responsible also involves being ready to face the other and answer to the demands that emerge from such an encounter [29]. Responsibility involves preparing oneself both to be responsible for, or attributability, and responsible toward, or accountability.

If conceived in terms of attributability, the responsibility of project selectors encompasses all that can be associated to the project selection process for purposes of praise or blame. Correspondingly, two conditions must be fulfilled for such a moral attribution to be valid: first, the selector must have had effective control over the process with the freedom to decide; second, the selector could reasonably gain sufficient awareness of what is involved. If these conditions are fulfilled, responsibility covers anything from unintentional benefits to lost opportunities through foreseeable nuisance. On this account, the attributability view of responsibility is a strong inducement for decision-makers to enter into a critical reflexive praxis about the premises and consequences of their criteria 
and choices. It might be a matter of (re-)connecting with the less visible aspects of the project, such as the social conditions of production at an indirect supplier or the long term environmental impact of the project's by-products. Or it can be a matter of using one's control of the process to introduce self-willed limits out of concerns for social rules, professional norms, or simply ordinary decency. Responsibility turns control and knowledge into key imperatives.

The responsibility of project selectors conceived of in terms of accountability is different. It also follows from one's freedom to act, but in the sense that one is only free inasmuch as one is ready to answer for the consequences of one's acts [30]. The accountability view of responsibility consists in being ready to actually meet those who for some reason to think that they have a say in the project. The term "actually" is pivotal in that it excludes ritualistic or purely formal answers; so is the term "meet" that refers to the personal involvement that emerges from face-to-face situations, where face-to-face is to be understood not only in a literal but also in a metaphorical sense; and so is the term "say" that indicates that one has to do with the live dynamic of the saying rather than the insensitive logic of the said [29]. Practically, accountability refers to a practice of answerability, for example through an enactment of corporate social responsibility that is anchored in a genuine sensibility to the concerns of those most vulnerable to the effects of corporate conduct [31]. Accountability clearly illustrates the positive side of responsibility, for example, when it comes to establish the legitimacy and increase the acceptance of a project.

A critical issue under such definitional circumstances is that responsibility can become virtually endless. Selectors can, however, not be held responsible for all that happens before, during, and after a project. This would put their agency under an endless demand. Moreover, even conducted as responsibly as possible, a project can, as any venture, nevertheless end up imposing negative moral externalities on third parties [32]. The scope of a selector's responsibility needs therefore to be delineated.

A way to delineate selectors' responsibility is to observe that projects are complex socio-technical arrangements that are called in by a parent organisation to serve some kind of purpose. As such projects fit the definition of "service" adopted by service science, namely "the application of scientific, management, and engineering disciplines to tasks that one organization performs beneficially for and with another" [33]. Projects can be seen as services offered to the parent organisation, and considering that a key characteristic of services is to be coproduced by service providers and service consumers [34], projects can therefore be seen as co-produced by the project team and the parent organisation with the project selector acting a proxy for the latter. Viewing project selectors as coproducers of the project settles the scope of their responsibility: their responsibility is to apply their judgement [35] to their actual share in the co-production of the project. This even delineates their responsibility in time: project selectors are not responsible for all the decisions taken after the selection, for example 
poor maintenance, but remain responsible over time for what derives from their selection decision, for example a poor original design.

Creating the conditions for something to happen is a creative act. Even if selectors do not participate to the execution phase of the project, they are co-producers of the project. This is an expression of power that involves a corresponding responsibility for what one does, and before and toward those who are affected. In the next section, we detail the dimensions of this responsibility when applied to the various phases of project selection.

\section{An ethical model of project selection}

Sivvathanu Pillai et al. [36] assert that project selection is composed of three phases: initial screening, detailed evaluation, and project selection. Whereas we agree with the relevance of deconstructing project selection into phases for analytical purposes, we have some concerns about their terminology. To begin with the third phase, we find inappropriate for semantic as well as logical reasons to label a part in the same terms as the whole. We therefore rather speak of a decision phase instead. About their second phase, we are not too sure about the difference in nature between initial screening and detailed evaluation. Both seem to refer to an appraisal of the projects in competition, albeit with different degrees in detail and formalism. We prefer to combine the two in an appraisal phase. Finally, we believe that it is important to even consider how proposals are initiated as a part of project selection. Pillai et al. [36] take this part of the process for granted and leave it outside their scheme; we make it an integral part of the selection process and call it an initialisation phase.

As we see it, project selection can be deconstructed for analytical purposes into an initialisation phase, an appraisal phase, and a decision phase. The initialisation phase starts with how one announces the opening of a selection process. It continues with how proposals are solicited, and how participants are informed of the terms of the selection, among which are the selection criteria. It ends with the actual collection of proposals. The appraisal phase includes the various screenings and evaluations that may take place, from formal to substantial ones and from cursory to thorough ones. The decision phase, finally, consists of how one decides about which project(s) is(are) to be retained. This includes who participates in the decision process, and how any decision is communicated to those who have made a proposal and others. Although corresponding to a logical and chronological order, this explication of the selection process as composed of phases is to be seen as analytical rather than practical. It does not necessarily correspond to the practicalities of project selection as organisational actors may experience them since actions and retro-actions between the various points in the process often give the impression that actual selection processes lack the sorts of linear logic that our model assumes. But it provides a general outline of the nature of the project selection process as a managerial situation. 
By combining these three phases of initialisation, appraisal, and decision with an approach to responsibility in terms of attributability and accountability, one obtains a model to appreciate the moral responsibility involved by the multifaceted and shifting power of selecting projects. (See Table 1. The moral responsibility of project selectors). We will now detail this model.

\begin{tabular}{|c|c|c|c|}
\hline & & \multicolumn{2}{|c|}{ Responsibility } \\
\hline \multirow{7}{*}{ 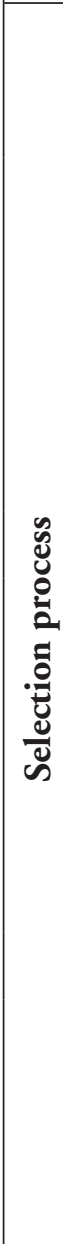 } & & Attributability & Accountability \\
\hline & & \multicolumn{2}{|c|}{ Main virtue: Openness } \\
\hline & $\begin{array}{c}\text { Initialisation } \\
\text { phase }\end{array}$ & $\begin{array}{l}\text { Ethical communication: } \\
\text { - quantity } \\
\text { - quality } \\
\text { - relation } \\
\text { - manner }\end{array}$ & $\begin{array}{l}\text { Ethics of hospitality: } \\
\text { - unconditional } \\
\text { invitation } \\
\text { - maintained control }\end{array}$ \\
\hline & & \multicolumn{2}{|c|}{ Main virtue: Correctness } \\
\hline & $\begin{array}{c}\text { Appraisal } \\
\text { phase }\end{array}$ & $\begin{array}{l}\text { Evaluation deontology: } \\
\text { - Systematic Inquiry } \\
\text { - Competence } \\
\text { - Integrity/Honesty }\end{array}$ & $\begin{array}{l}\text { Stakeholder ethics: } \\
\text { - Respect for people } \\
\text { - Responsibilities for } \\
\text { general and public } \\
\text { welfare }\end{array}$ \\
\hline & & \multicolumn{2}{|c|}{ Main virtue: Integrity } \\
\hline & Decision phase & $\begin{array}{l}\text { Consequentialism: } \\
\text { - efficiency } \\
\text { - effectiveness } \\
\text { (in context) }\end{array}$ & $\begin{array}{l}\text { Ethics of justice: } \\
\text { universal fairness }\end{array}$ \\
\hline
\end{tabular}

Table 1: The moral responsibility of project selectors

\subsection{Initialisation phase}

The purpose of the initialisation phase in project selection is to attract and collect the best possible proposal or proposals. A way to bare the specific moral responsibility that initialisation involves is to consider initialisation as an invitation made to possible contributors, who can be as few as one, to come forward with proposals. 
An invitation is a communicative act, and selectors will be praised or blamed on the basis of their ability to communicate rightly. The classic maxims enunciated by Grice [37] about the quantity, quality, relation, and manner of communication may serve as a practical guide to what this involves.

- The maxim of quantity states that communication should be as informative as is required although not more informative than is required. For selectors, this involves providing adequate information about the sorts of projects the parent organisation is interested in, detailing conditions for eligibility, presenting the selection criteria, and possibly also the time schedule for the process.

- The maxim of quality requires that communication be true: one is not to say something that one believes to be false or for which one lacks adequate evidence. For selectors, this might involve taking a clear stand for clarity in the process against pressures coming from the parent organisation to serve parochial or hidden interests.

- The maxim of relation requires that one be relevant. For selectors, this may involve discouraging project proposals that are beside the point as no one has an interest in overflowing the process with proposals that lack appropriateness. This may inversely involve saying no to eligibility or selection criteria that may prove to be excluding beyond motivated reasons, or simply discriminatory.

- Finally, the maxim of manner states that one be perspicuous. Grice spells out that one should avoid obscurity of expression, ambiguity or unnecessary prolixity, and orderliness. This can serve as guiding principles for how to practically design a call for participation.

Attributability stages a demand for ethical communication. As the Credo for Ethical Communication of the American National Communication Association [38] asserts, this involves a commitment to truthfulness, accuracy, honesty, and reason ${ }^{1}$.

An invitation is, however, not only a technical matter of communication. In terms of accountability, it is an act of hospitability upon which the selector offers to host project proposals. But an inherent problem of hospitality, as Jacques Derrida [39] observes, is that it involves a contradictory mix of unconditional abandon and the need for maintained control. The law of pure hospitality is

\footnotetext{
${ }^{1}$ There is a clear consonance between these principles and the discourse ethics of Jörgen Habermas. Due to the complex character of the latter's philosophy, this is something that we can however not discuss here. We refer instead to: Meisenbah R J. Habermas's Discourse Ethics and Principle of Universalization as a Moral Framework for Organizational Communication. Management Communication Quarterly. 2006; 20: 39-62.
} 
underpinned by altruism. It asserts a precedence of the Other, and it cannot be true if conditioned to the guest fulfilling pre-defined requirements. To be a host is to accept to expose oneself to surprises. This might seem far from project selection, but it is not. Path-breaking ideas come with a surprise. If the idea of inviting proposals is to be meaningful, otherness has to be given precedence. The Other stands for that which is not necessarily the same, known, or imaginable. An unconditional hospitality is a condition for radical creativity to come to light and shape the future, for example in terms of conception, design, or realisation. If narrowly conditioned, future projects might otherwise simply replicate the past and present. Project selectors need to be ready not only for proposals that actually answer to the demand of the parent organisation; they even need to remain open for proposals that intend to re-shape the competitive area and the rules of the game [40].

At the same time, the laws of hospitality curtail unconditional hospitality. The host has to keep some control of the house to be able to maintain actual conditions of hospitality. Guests cannot be allowed to be a parasite or, even less, to threaten the other Others who already enjoy hospitality or might need it in the future. Selectors need to exert a minimum of control over the process to be in a position to take diligent care of all the proposals that have been sent in. They are accountable for their ability to keep their guest-proposals under control, even if this implies filtering and choosing among them and thereby exerting on them the sort of excluding violence that true hospitality forbids.

Openness is how selectors can accommodate the contradictions of hospitality. It combines curiosity with receptivity, accessibility with tolerance, and is characterized by a readiness to experience even the deeply unfamiliar. Since it is also a way to communicate rightly, it is probably the best moral guarantee they have to meet the demands of attributability and accountability of the initialisation phase.

\subsection{Appraisal phase}

The next stage of the selection process is the appraisal phase. Appraisal consists in the screening and evaluating of the proposal or proposals in the selectors' presence, comparing them one to another or simply to the zero solution. It is a matter of appropriate deontology or professional obligations. There are, as discussed in section 2 above, numerous models and methods to select projects. Our purpose is not to evaluate which of them is to be preferred but to draw a general course of moral action when they are to be brought into use.

The American Evaluation Association [41] singles out five principles to guide the work of evaluators. As we see it, the first three relate to the attributability dimension of responsibility whereas the last two relate to its accountability dimension. Slightly adapted to the work situation of selectors, the first three principles recommend that: 
- Selectors proceed to systematic, data-based inquiries. Not only should all proposals be reviewed, but these should also be reviewed in totality.

- Selectors provide a competent performance to stakeholders. This involves a professional handling of the retained selection technique(s), inclusive of a critical reflection on their appropriateness and limits as evaluative tools. This also involves a respect for the cultural diversity of the material involved; selectors are required to reflect self-critically on their world-view and bare the culturally-biased assumptions that follow, for example, from their own professional background.

- Selectors ensure the honesty and integrity of the entire evaluation process. This involves aiming at a clear representation of essential matters such as costs, time schedules, and scope of results, at the exclusion of distortions due to methodological or procedural constraints. This also involves an avoidance of any conflict of interest (or appearance of a conflict). Selectors should even keep the evaluation process within reasonable time limits.

In brief, selectors are expected to be systematic, competent, and honest, and can be blamed if such is not the case.

The last two guiding principles set forth by the American Evaluation Association depict how evaluators should relate to stakeholders. With a slight adaptation again, they outline their responsibility in terms of accountability.

- Selectors respect the security, dignity, and self-worth of the respondents, project teams, parent organisation, and other stakeholders with whom they interact.

- Selectors articulate and take into account the diversity of interests and values that may be related to the general and public welfare.

Selectors are not only accountable for their choices toward primary stakeholders, such as the project team or the parent organisation. Expected to adopt a multipartisan perspective, they are also accountable toward secondary stakeholders such as the public at large or the environment (on stakeholder management, see [42]). This is all the more important that the quality of the network built around a project is decisive to its success [40], this quality being a function of the legitimacy of the project in the eyes of its stakeholders.

More specifically, the accountability of selectors is a future-oriented one. Selectors are not only to answer for the actual consequences of their past decisions; they might have to answer even about potential consequences of futures ones. As a managerial technology, project selection is encompassed by 
the moral imperative set by Hans Jonas [43] to technological choices: "Act so that the effects of your action are compatible with the permanence of genuine human life." This is an imperative that prohibits choices that are destructive of the future possibility of such life, or that compromise the conditions for the indefinite continuation of humanity on earth. Practically, selectors are required to incorporate in the proposals even those negative effects that project proposals do not refer to but might bring about. They have a duty to see beyond the need formulated by the parent organization or the descriptions in the proposals and take into account the long term consequences of the project, for close as well as remote stakeholders.

If openness is the cardinal virtue of selectors during the initialisation phase, the virtue they need to demonstrate during the appraisal phase is correctness. Correctness is basically the ability to act in conformity with the rules of evaluation. Selectors are expected to give signs of a genuine understanding of project proposals. They are likewise expected to produce, with diligent efficacy, grounded, balanced, and fair appraisals. Such a responsibility requires not the least a strict procedural congruency.

\subsection{Decision phase}

The last phase of the selection process is the decision phase. At face value, it comprises the actual choice of project(s) and the communication of the decision. This is however less simple than it seems. As Nils Brunsson convincingly argues [44], decisions cannot be simply equated with individual intentionality and choices; decisions are social phenomena that involve locally institutionalised rules of rationalities, patterns of actions, or ways to look at consequences. Examples abound of selectors who are imposed by parameters that curtail their possibilities to make the finest decisions, or even effectively decouple the decision phase from the foregoing evaluation. More than any other phase of the selection process, the decision phase is embedded in the social becoming of the organisation. This is where selectors need to take fully into account that they manoeuvre within the realm that Weber [27] calls an ethics of responsibility. Their decisions cannot only rely on their pure ethical convictions as individuals. They need to resist pressures, inclusive of nepotism or corruption, and face the moral imperative to consider the foreseeable consequences of their agency, for others and the environment.

With this caveat in mind, it is possible to claim that during the decision phase selectors have a responsibility of efficacy in terms of attributability, and a responsibility of justice in terms of accountability. To begin with efficacy, selectors have a responsibility to select "good" projects. Good is bracketed to emphasise that it is not a matter of absolute but of negotiated reality. To a parent organisation with low financial solidity, a selector may recommend a project with small but dependable net present value rather than another with 
higher outcomes but also higher risk. Likewise, selectors may not recommend a parent organization with particularly high demands on its reputation, a project that, although ethically right, might be hard to communicate to the project's stakeholders. Contingencies determine efficiency, effectiveness, and the fit between them.

As agents [11], selectors are expected to make decisions that meet the parent organisation's needs in the best possible way. Blame or praise is measured in terms of the qualitative consequences of their verdict. Consequentialism rules attributability in the decision phase. Selectors have a responsibility to elicit the solution(s) with the best possible outcome(s) for the parent organization. This involves raising their gaze beyond the project itself and contextualising their evaluation within the operational and strategic processes of the parent organisation. Selectors need to enter a delicate operation of sense-making where they forecast the project in time and (social) space to see how it might suit the parent organisation. How far they are to go is a matter of negotiation: whereas selectors can be blamed for choosing a poorly designed project, for example in terms of cost prevision or waste management, they can hardly be held responsible for unexpected problems or changes in the environment. Their responsibility is limited to what they can reasonably foresee and therefore control, in scope as well as in time.

What makes things more complicated is that the parent organisation is not the only party to whom selectors might owe an account. Other stakeholders may raise powerful demands for accountability, for example those whose projects have not been retained, those who are directly affected by the selected project(s), or any group that thinks of itself as a legitimate spokesperson for an interest, for example a particular animal specie. Selectors need to be ready to face these and enter a dialogue. Since project selection is likely to prompt a demand for social and environmental justice among stakeholders, selectors might thus be advised to use John Rawl's [45] hypothetical veil of ignorance when making their decision. Leaving out for an instant that they are an agent of the parent organisation, they should ask themselves what they would think of the project if they would be behind a veil that occludes their own or any other person's social position, today as well as tomorrow. Universal fairness: is the project to worsen the life situation of the already worst-off members of society? Pragmatically, such an interrogation might protect the parent organization from unpleasant surprises. But first and foremost, it pertains to the individual responsibility that anyone with a say needs to endorse in the perspective of a society of self- and mutual respect.

The responsibility of selectors in the decision phase is multi-sided, even contradictory. It is also hard to formalise. Selectors need to resist pressures, contextualise their views, and trade among competing interests. Integrity is the third virtue they need, besides openness and rectitude, to carry out their 
moral mission. It is an ability to make and stick to judgements that maintain the completeness of (their sense of) their function and responsibilities.

\section{Concluding remarks}

It is a formalised view of responsibility that we propose here. In actual organisational contexts, the actual taking of such a responsibility can prove to be problematic, even perilous for the individual [46]. Business life brings managers into the subjection of structural constraints that curtail their possibilities to make decisions and act in ways that systematically comply with their moral judgement. A full model of managerial responsibility should therefore need to pay a more perceptive consideration to goal ambiguities, power games, local individual and group agendas, routines and other culturally determined behaviours, together with performance imperatives, the logic of the incentive system, the nature of competition, the efficiency of the moral support structure, or the ethical history of the organisation. Likewise, projects should not simply be addressed as purposeful instruments to achieve a pre-determined goal but as social practices embedded [5] in symbolic, emotional, and political content [47] with a life of their own. Many factors can affect a project selector's decision making, and (moral) selection is always contextual.

Our purpose to outline a model to appreciate the moral responsibility of project selectors should be viewed against the backdrop of this contextual embeddedness of project selection. We do not propose another formal ethical decision-making model $[48,49,50]$, but a means for selectors to increase their awareness that their choices involve a moral dimension. One of our assumptions is that being aware of one's responsibility is a decisive step toward moral decision-making. We even intend to provide selectors with a means to orient themselves to the nature of this responsibility, taking into consideration the contextual circumstances in which they act. Actual contextuality cannot be put into a model, though. It can only be made sense of by those who are part of it and are in a position to reflect upon it. Our purpose is to support the reflection of selectors toward a morally grounded practice.

Project selection involves responsibility at each and every stage of the process. In short, selectors have to combine openness with correctness and integrity. It is not only the conditions proper to the project or its outcomes that matter. Selectors also have a responsibility to manage the selection process in a fair way. Blame or praise can pertain as much to the project's nature as to the selection process itself. Likewise, being able to account for one's decision, whether to one's principal that is the parent organisation or to one's agent that is the project team, is only one side of accountability. Selectors also need to be ready to face those whose proposals have not been retained or those who might be negatively affected by the project. Selectors should be aware that their moral responsibility is multidimensional. 
In practice, though, this responsibility cannot be endless. Selectors cannot be held responsible for all that can possibly happen in and around, or during and after a project. It is as important to delineate responsibility as to underscore its unavoidability. Stretching responsibility to infinity would have the paradoxical effect to annihilate the mere idea that selectors have an actual moral responsibility - which is our claim.

Because they participate in the design and monitoring of the selection process, selectors are co-producers of the project. The possibility to say "yes" or "no" is a creative act. The outline of their creative power determines the outline of their responsibility: the two superimpose perfectly. An acid test could therefore be made by answering the following question: By selecting a project, am I ready to consider myself as its coproducer, and therefore prepared to be held responsible, whether for blame or praise, and to accept that I owe an answer for my selection both to those involved in the project or those simply effected by it? Although imperfect, this question could serve as a vade mecum to assess moral responsibility in project selection. 


\section{References}

1 Maylor, H. (2005) Project Management. Harlow (UK): Prentice Hall Financial Times.

2 Kadefors, A. (2004) Trust in project relationships — Inside the black box. International Journal of Project Management 22(3): 175-182.

3 Labuschagne C, Brent A C, Claasen S J. Environmental and social impact considerations for sustainable project life cycle management in the process industry. Corporate Social Responsibility and Environmental Management 2005; 12: $38-54$.

4 Lundin, R. A. and Söderholm, A. (1995) A theory of the temporary organization. Scandinavian Journal of Management 11(4): 437-455.

5 Manning, S. (2008) Embedding projects in multiple contexts - A structuration perspective. International Journal of Project Management 26(1): 30-37.

6 Söderlund, J. (2005) Projektledning och projektkompetens. Malmö: Liber.

7 Mantel, S. J. Jr., Meredith, J. R., Shafer, S. M. and Sutton, M. M. (2008) Project management in practice. Hoboken (NJ): John Wiley \& Sons, Inc, page 9.

8 Shtub A, Bard J F, Globerson S. Project management engineering, technology, and implementation. Englewood Cliffs (NJ): Prentice Hall, Inc. 1994

9 Lefley, F. (2004) An assessment of various approaches for evaluating project strategic benefits: Recommending the strategic index. Management Decision 42(7): 850-862.

10 Dey, P. K. (2006) Integrated project evaluation and selection using multipleattribute decision-making technique. International Journal of Production Economics 103(1): 90-103.

11 Eisenhardt, M. K. (1989) Agency theory: An assessment and review. Academy of Management Review 14(1): 57-75.

12 Sung, J. (2005) Optimal contracts under adverse selection and moral hazard: A continuous-time approach. Review of financial studies 18(3): 1021-1073.

13 Barron, J. M. and Waddell, G. R. (2003) Executive rank, pay and project selection. Journal of Financial Economics 67 (2): 305-349.

14 Sung, J. (1995) Linearity with project selection and controllable diffusion rate in continuous-time principal-agent problems. The Rand Journal of Economics 26 (4): 720-743.

15 Gray, C. F. and Larsson, E. W. (2008) Project management - The managerial process. Boston (MA) and London: Mc Graw-Hill Irwin.

16 Chapman, C. B., Ward, S. C. and Klein, J. H. (2006) An optimised multiple test framework for project selection in the public sector, with a nuclear waste disposal case-based example. International Journal of Project Management 24 (5): 373-384 
17 Puthamont, S. and Charoenngam, C. (2007) Strategic project selection in public sector: Construction projects of the Ministry of Defence in Thailand. International Journal of Project Management 25 (2): 178-188.

18 Mantel, J. R. and Meredith, S. J. Jr. (2006) Project Management - A Managerial Approach. Wiley International Student version.

19 Kinsella, S. M. (2002) Activity-based costing: Does it warrant inclusion in a guide to the project management body of knowledge (PMBOK guide)? Project Management Journal 33 (2): 49-56.

20 Lee, J. W. and Kim, S. H. (2001) An integrated approach for interdependent information system project selection. International Journal of Project Management 19 (2): 111-118.

21 Archer N. P. and Gasemzadeh, F. (1999) An integrated framework for project portfolio selection. International Journal of Project Management 17(4): 207-216.

22 Carlsson, C., Fuller, R., Heikkila M., and Majlender, P. (2007) A fuzzy approach to $\mathrm{R} \& \mathrm{D}$ project portfolio selection. International Journal of Approximate Reasoning 44(2): 93-105.

23 Wei, C. C., Liang, G-S, and Wang, M-J. (2007) A comprehensive supply chain management project selection framework under fuzzy environment. International. Journal of Project Management 25 (6): 627-636.

24 Lawson, C. C., Longhurst, P. J., and Ivey, P. C. (2006) The application of a new research and development project selection model in SMEs. Technovation 26(2): 242-250.

25 Elkington, J. (1998) Cannibals with forks - The triple bottom line of 21st century business. Gabriola Island, BC (Canada), New Society Publishers.

26 Carroll, A. B. (1979) A Three-Dimensional Conceptual Model of Corporate Performance. Academy of Management Review 4(4): 497-505.

27 Weber, M., (1987) Politics as a Vocation [1919]. In W G Runciman (Ed) Max Weber. Selections in Translation (translated by E. Matthews), pp. 212-25. Cambridge: Cambridge Uni versity Press.

28 Eshleman A. Moral Responsibility. The Stanford Encyclopedia of Philosophy (Fall 2004 Edition), Edward N. Zalta (ed.), URL = <http://plato.stanford.edu/archives/ fall2004/entries/moral-responsibility/>; February 5, 2008.

29 Bevan, D. and Corvellec, H. (2007) The impossibility of corporate ethics - For a lévinasian approach to managerial ethics. Business Ethics - A European Journal 16(3): $208-219$.

30 Fayol F. Responsabilité, déontologie, éthique. Cadres-CFDT, 401-402: 5-11.

31 Roberts, J. (2003) The manufacture of corporate social responsibility: Constructing corporate sensibility. Organization 10(2): 249-265.

32 Gowri, A. (2004) When responsibility can't do it. Journal of Business Ethics 54: 33-50. 
33 Spohrer, J. (2008) Services sciences, management, and engineering (SSME) and its relation to academic disciplines. In B. Stauss, Kai Engelmann, Anja Kremer, Achim Luhn (Editors) Services science: Fundamentals, challenges and future developments. Berlin: Springer, page 2.

34 Grönroos, C. (2007) Service management and marketing: Customer management in service competition. Chichester: Wiley.

35 Bertelli, A. M. and Lynn, L. E. Jr. (2003) Managerial responsibility. Public Administration Review 63(3): 259-268.

36 Pillai, A. S., Joshi, A., and Rao, K. S. (2002) Performance measurement of R\&D projects in a multi-project, concurrent engineering environment. International Journal of Project Management 20(2): 165-177.

37 Grice, H. P. (1975) Logic and conversation. In P Cole, J L Morgan (Eds) Syntax and Semantics, Vol.3, pp. 45-47. New York: Academic Press.

38 National Communication Association (US). Credo for ethical communication (approved by the NCA Legislative Council in 1999), URL $=<$ http://www.natcom. org/nca/Template2.asp?bid=374>; May 2, 2008.

39 Derrida, J. (2000) Of Hospitality: Anne Dufourmantelle invites Jacques Derrida to respond. Stanford: Stanford University Press.

40 Cova, B. and Hoskins, S. (1997) A twin-track networking approach to project marketing. European Management Journal 15(5): 546-556.

41 American Evaluation Association (2004) Guiding principles for evaluators, URL = <http://www.eval.org/Publications/GuidingPrinciplesPrintable.asp; May 9, 2008.

42 Friedman, A. F. and Miles, S. (2006) Stakeholders - Theory and Practice. Oxford: Oxford University Press.

43 Jonas, H. (1984) The imperative of responsibility: In search of an ethics for the technological age. Chicago: University of Chicago Press.

44 Brunsson, N. (2007) The consequence of decision-making. Oxford: Oxford University Press.

45 Rawl, J. (1999) A theory of justice. Harvard: Harvard University Press. [original published 1971]

46 Jackall, R. J. (1988) Moral mazes—The world of corporate managers. New York and Oxford: Oxford University Press.

47 Hodgson, D. and Cicmil, S. (2006) Making projects critical. Houndmills (UK): Palgrave Macmillan.

48 Bartlett, D. (2003) Management and business ethics: A critique and integration of ethical decision-making models. British Journal of Management 14:223-235.

49 Fang, M-L. (2006) Evaluating ethical decision-making of individual employees in organizations - An integration framework. Journal of American Academy of Business 8(2): 105-112.

$50 \mathrm{McDeVitt}, \mathrm{R}$., Giaponi, C., and Tromley, C. (2007) A model of ethical decision making: the integration of process and content. Journal of Business Ethics 73: 219-229. 